\title{
Recurrent Childhood Central Nervous System Embryonal Neoplasm
}

National Cancer Institute

\section{Source}

National Cancer Institute. Recurrent Childhood Central Nervous System Embryonal

Neoplasm. NCI Thesaurus. Code C114836.

The reemergence of childhood central nervous system embryonal neoplasm after a period of remission. 